\title{
Study of perinatal outcome of labour complicated with meconium stained liquor
}

\author{
Asmita N. Patil, Misbah M. Inamdar*, Jaynarayan B. Senapati
}

Department of Obstetrics and Gynecology, RGMC and CSMH, Kalwa, Thane, Maharashtra, India

Received: 08 August 2018

Accepted: 14 August 2018

\section{*Correspondence:}

Dr. Misbah M. Inamdar,

E-mail: miisbah23@gmail.com

Copyright: (C) the author(s), publisher and licensee Medip Academy. This is an open-access article distributed under the terms of the Creative Commons Attribution Non-Commercial License, which permits unrestricted non-commercial use, distribution, and reproduction in any medium, provided the original work is properly cited.

\begin{abstract}
Background: Meconium stained amniotic fluid occurs in 9 to $20 \%$ of deliveries. It has long been implicated as a factor influencing foetal wellbeing during the intrapartum and postpartum period. Many authors have suggested that the type and the time of passage of meconium are most significant factors affecting foetal outcome. This study was carried out to find out the effect of meconium stained liquor during labour and its perinatal outcome.

Methods: This prospective cross sectional and comparative study was carried out in a tertiary care hospital over a period of 1 year. The study group comprised of 118 women having MSAF during labour and the comparative group of 118 women with clear amniotic fluid which were randomly selected. The demographic data, obstetrical history, intrapartum findings and Apgar score were documented on predesigned proforma. Data collected was analysed using student t-test, chi square test, $\mathrm{Z}$ test for comparison of proportions and coefficient of variation for comparison of consistency of distributions.

Results: Out of 1192 cases studied 118 cases showed presence of meconium stained liquor (9.89\%). Caesarean section was performed in $41.52 \%$ cases with meconium stained liquor versus $31.35 \%$ in clear liquor group. Apgar score at 1 minute was significantly lower in meconium stained liquor $(\mathrm{p}<0.01)$. In meconium stained liquor group $42.37 \%$ foetuses had normal, $36.44 \%$ had suspicious and $21.18 \%$ had abnormal heart rate patterns respectively. There was no significant difference in the number of cases requiring NICU admission in meconium stained liquor (14.4\%) and clear liquor groups $(9.3 \%)(\mathrm{Z}=1.214, \mathrm{P}>0.05)$.

Conclusions: Meconium staining is a commonly observed phenomenon. labour complicated with thick meconium stained liquor should ideally be categorised in to high risk obstetrics and managed in tertiary care with consultant obstetrician, consultant neonatologist and NICU in order to improve the perinatal outcome.
\end{abstract}

Keywords: Foetal outcomes, LSCS, Meconium stained liquor, Neonatal intensive care

\section{INTRODUCTION}

Meconium stained amniotic fluid is commonly found in obstetrics. It occurs in 9 to $20 \%$ of deliveries. Meconium passage into amniotic fluid may be an ante partum or intra partum event.

Presence of meconium stained amniotic fluid is a serious sign of foetal compromise, which is associated with increase in perinatal morbidity and mortality, whereas clear amniotic fluid on the other hand is considered reassuring. ${ }^{1,2}$

Meconium stained liquor has long been implicated as a factor influencing foetal wellbeing during the intrapartum and postpartum period. The exact aetiology of meconium stained amniotic fluid remains unclear as the knowledge of the underlying mechanism is still incomplete. 
Conflicting results have been reported regarding foetal outcome when the amniotic fluid is meconium stained. Some investigators have reported an increase incidence of foetal distress and neonatal morbidity, others say only when other signs of asphyxia (foetal heart rate decelerations and foetal acidosis) are present. ${ }^{3-6}$

Many authors have suggested that the type of meconium and the time of passage of meconium are most significant factors affecting foetal outcome. In addition, if foetal heart rate abnormalities are also present, the risk to the foetus has been found to be significantly compounded. Presence of meconium and non-reassuring FHR pattern necessitates urgent intervention. On the other hand, reassuring FHR pattern and thin meconium can be managed expectantly. ${ }^{7}$

This study was carried out to find out the effect of meconium stained liquor during labour and its perinatal outcome.

\section{METHODS}

In this prospective cross sectional and comparative study, total 1192 cases admitted in labour ward of Lourdes hospital, cochin, Kerala were evaluated for a period of one year at Lourdes hospital, Cochin, Kerala.

The study Group comprised of 118 women admitted in labour and having meconium stained amniotic fluid and the comparative group which were randomly selected comprised of 118 women in labour with clear amniotic fluid.

\section{Inclusion criteria}

All singleton full term pregnant women in labour.

\section{Exclusion criteria}

- Breech presentation.

- Anomalous foetus.

- Preterm labour.

- Intra uterine foetal death (macerated still birth).

$\mathrm{T}$ The detailed gynaecological and obstetric history noted and examination done after taking written informed consent.

Following parameters noted for data collection.

On admission: women name, age, time of admission and inpatient number recorded. Obstetric and medical history noted. Complete obstetric examination finding noted. Colour of the liquor noted, if meconium stained it was divided into 3 groups according to its consistency.

- Grade I (Thin) - light yellow.

- Grade II (Moderate) - green.

- $\quad$ Grade III (Thick) - dark green or brown, paste like.
During labour foetal heart rate monitoring was done using a stethoscope and continuous foetal heart rate monitoring was done in high risk cases.

The time when the meconium was noted and at what stage of dilatation of cervix and the associated foetal heart rate pattern were noted. Mode of delivery, time of delivery, Apgar score (1minute and 5 minute), weight and sex of each new born was noted. In cases admitted to NICU, number of days of stay neonatal intensive care unit and overall total days of hospital stay were noted.

According to hospital protocol oropharyngeal suctioning was done for each new born, but intubation or resuscitation was done according to new born resuscitation programme by American Heart Association and Indian Academy of Paediatrics.

Foetal outcome was measured by birth weight, Apgar score at 1 and 5 minutes, admission in Neonatal Intensive Care Unit, assessment of indication of admission in Neonatal Intensive Care Unit and neonatal deaths. All babies were followed up until discharge from the hospital.

Comparisons were made between meconium stained group and clear amniotic fluid group to find out whether any difference exists between the two groups in relation to mode of delivery and foetal outcome.

\section{Statistical analysis}

Data collected for the study was compiled and analysed using students't- test for comparison of means, chi square test for test of goodness of ratios, $\mathrm{Z}$ test for comparison of proportions and coefficient of variation for comparison of consistency of distributions.

\section{RESULTS}

Out of 1192 cases studied 118 cases showed presence of meconium stained liquor $(9.89 \%)$.

\section{Mode of delivery}

This analysis revealed that $52(44.06 \%)$ cases had spontaneous vaginal deliveries in meconium stained liquor versus $57(48.30 \%)$ in the clear liquor group, which was not statistically significant (chi square $=0.229$, p>0.05).

However, spontaneous vaginal deliveries were significantly less $(6.06 \%)$ in cases with thick meconium compared to those with moderate $(44.18 \%)$ and thin meconium stained liquor $(73.80 \%)$.

$14.40 \%$ cases had instrumental deliveries in meconium stained liquor whereas $20.33 \%$ in clear liquor group which was not statistically significant (chi square = 1.195, $\mathrm{p}>0.05)$. Among meconium stained liquor group 
$15.15 \%$ instrumental deliveries occurred in thick meconium, $13.95 \%$ in moderate meconium and $14.28 \%$ in thin meconium respectively. Caesarean section was performed in $41.52 \%$ cases with meconium stained liquor versus $31.35 \%$ in clear liquor group but the difference was not significant (chi square $=1.674, \mathrm{p}>0.05$ ). Among meconium stained liquor group caesarean deliveries were higher $78.78 \%$ in thick meconium, compared to $41.86 \%$ in moderate and $11.90 \%$ in thin meconium respectively (Table 1).

Table 1: Distribution of mode of deliveries in meconium stained and clear liquor.

\begin{tabular}{|c|c|c|c|c|c|c|c|c|c|c|}
\hline \multirow{2}{*}{$\begin{array}{l}\text { Mode of } \\
\text { delivery }\end{array}$} & \multicolumn{2}{|c|}{ Thick meconium } & \multirow{2}{*}{$\begin{array}{l}\text { Moderate } \\
\text { meconium } \\
\mathbf{n = 4 3}\end{array}$} & \multirow[b]{2}{*}{$\%$} & \multicolumn{2}{|c|}{$\begin{array}{l}\text { Thin } \\
\text { meconium }\end{array}$} & \multicolumn{2}{|l|}{ Total } & \multicolumn{2}{|c|}{ Clear liquor } \\
\hline & $n=33$ & $\%$ & & & $\mathrm{~N}=42$ & $\%$ & $\mathrm{~N}=118$ & $\%$ & $N=118$ & $\%$ \\
\hline $\begin{array}{l}\text { Spontaneous } \\
\text { vaginal delivery }\end{array}$ & 2 & 6.06 & 19 & 44.18 & 31 & 73.80 & 52 & 44.06 & 57 & 48.30 \\
\hline $\begin{array}{l}\text { Instrumental } \\
\text { delivery }\end{array}$ & 5 & 15.15 & 6 & 13.95 & 6 & 14.28 & 17 & 14.40 & 24 & 20.33 \\
\hline Caesarean delivery & 26 & 78.78 & 18 & 41.86 & 5 & 11.90 & 49 & 41.52 & 37 & 31.35 \\
\hline
\end{tabular}

\section{Foetal heart rate pattern}

In meconium stained liquor group $42.37 \%$ foetuses had normal heart rate pattern, $36.44 \%$ had suspicious foetal heart rate pattern and $21.18 \%$ had abnormal heart rate pattern. In clear liquor group 54.23\% had normal, $26.27 \%$ had suspicious and $19.49 \%$ had abnormal heart rate pattern, but the difference was not significant amongst the two groups. $(\mathrm{p}>0.05)$.
Among meconium stained liquor group normal foetal heart rate pattern was significantly low $(15.15 \%)$ in thick meconium compared to $37.20 \%$ in moderate and $69.04 \%$ in thin meconium stained liquor respectively. Suspicious heart rate pattern was seen in $39.39 \%, 48.83 \%$, and $21.42 \%$ in thick, moderate and thin meconium stained liquor respectively. Abnormal foetal heart rate was significantly high $45.45 \%$ in thick versus $13.95 \%$ in moderate and $9.52 \%$ in thin meconium stained liquor.

Table 2: Apgar score at 1 min.

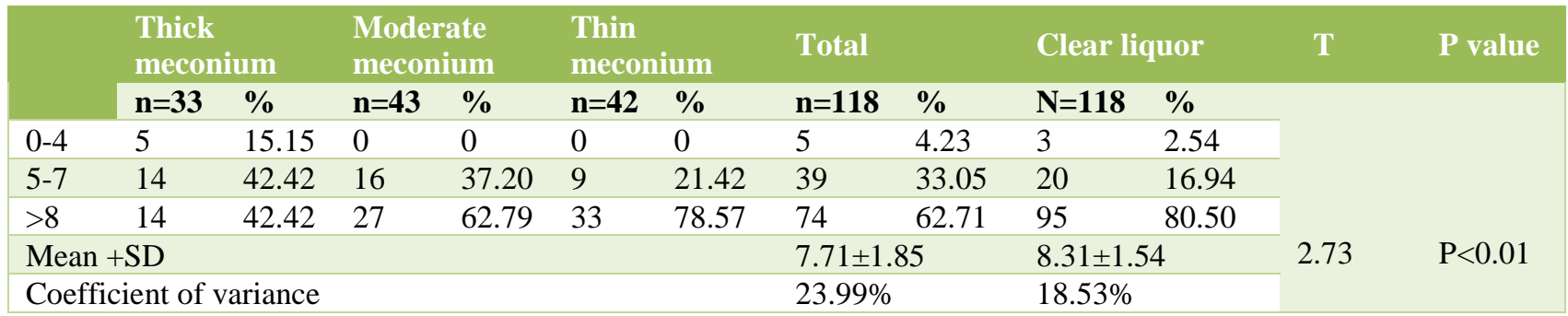

\section{Apgar score}

Apgar score at 1 minute was significantly lower in meconium stained liquor group compared to that in cases with clear liquor $(\mathrm{p}<0.01)$.

\section{Comparison between thick, moderate, thin meconium}

Thick (6.67 \pm 2.04$)$; Moderate 7.88 \pm 1.47 ; Thin $8.36 \pm 1.21$

Moderately thick meconium has significantly high Apgar score compared to thick meconium. $t=2.69(\mathrm{p}<0.01)$. Apgar score at $1 \mathrm{~min}$ is significantly low in thick meconium than thin meconium $\mathrm{t}=3.93$, $(\mathrm{p}<0.001)$. There is no significant difference in the moderately thick and thin meconium groups $t=1.622,(p>0.05)$ (Table 2$)$.
APGAR score at $5 \mathrm{~min}$ did not show any significant difference between meconium stained and clear group (p>0.05) (Table 3).

\section{Comparison between thick, moderately thick and thin meconium}

Thick 7.88 \pm 1.71 ; Moderate 8.65 \pm 0.97 ; Thin $8.93 \pm 0.43$

Moderately thick meconium had significantly higher Apgar score at 5 minute compared to thick $\mathrm{t}=2.44$ $(\mathrm{p}<0.05)$. Apgar score at 5 minute is significantly low in thick meconium compared to thin. $t=3.75(p<0,001)$. There is no significant difference between Apgar score at 5 minute in thin and moderately thick meconium. $\mathrm{t}=1.71(\mathrm{p}>0.05)($ Table 3$)$. 
Table 3: APGAR score at 5 mins.

\begin{tabular}{|c|c|c|c|c|c|c|c|c|c|c|c|c|}
\hline & \multicolumn{2}{|c|}{$\begin{array}{l}\text { Thick } \\
\text { meconium }\end{array}$} & \multicolumn{2}{|c|}{$\begin{array}{l}\text { Moderate } \\
\text { meconium }\end{array}$} & \multicolumn{2}{|c|}{$\begin{array}{l}\text { Thin } \\
\text { meconium }\end{array}$} & \multicolumn{2}{|l|}{ Total } & \multicolumn{2}{|c|}{ Clear liquor } & \multirow[t]{2}{*}{$\mathrm{T}$} & \multirow[t]{2}{*}{ P value } \\
\hline & $n=33$ & $\%$ & $n=43$ & $\%$ & $n=42$ & $\%$ & $n=118$ & $\%$ & $N=118$ & $\%$ & & \\
\hline $0-4$ & 1 & 3.03 & 0 & 0 & 0 & 0 & 1 & 0.84 & 1 & 0.84 & \multirow{5}{*}{1.2} & \multirow{5}{*}{$\mathrm{P}>0.05$} \\
\hline $5-7$ & 10 & 30.30 & 5 & 11.62 & 1 & 2.38 & 16 & 13.55 & 9 & 7.62 & & \\
\hline$>8$ & 22 & 66.66 & 38 & 88.37 & 41 & 97.61 & 101 & 85.59 & 106 & 89.83 & & \\
\hline \multicolumn{3}{|c|}{ Mean \pm SD } & & & & & \multicolumn{2}{|c|}{$8.53 \pm 1.22$} & \multicolumn{2}{|c|}{$8.71 \pm 1.03$} & & \\
\hline \multicolumn{3}{|c|}{ Coefficient of variance } & & & & & $14.30 \%$ & & $11.83 \%$ & & & \\
\hline
\end{tabular}

\section{Neonatal resuscitation}

Immediate oropharyngeal suctioning was needed in $65.24 \%$ neonates in the meconium stained group whereas $88.13 \%$ in clear liquor group which had a statistical difference (chi square $=4.0248, p<0.05$ ). Total number of cases requiring immediate oropharyngeal suctioning was significantly higher in clear liquor group than meconium stained liquor group. $39.39 \%, 65.11 \%$ and $85.71 \%$ of thick, moderate and thin meconium stained liquor needed immediate oropharyngeal suctioning respectively.

Endotracheal intubation for suctioning followed by extubation registered significantly higher number of cases (20.33\%) in meconium stained liquor compared to clear liquor $(3.38 \%)$. (chi square $=14.28, \mathrm{p}<0.001$. In cases with thick, moderate and thin meconium stained liquor, $27.27 \%, 23.25 \%, 11.90 \%$ cases required the same respectively.

Table 4: Immediate resuscitation.

\begin{tabular}{|c|c|c|c|c|c|c|c|c|c|c|}
\hline \multirow{2}{*}{$\begin{array}{l}\text { Immediate } \\
\text { management }\end{array}$} & \multicolumn{2}{|c|}{$\begin{array}{l}\text { Thick } \\
\text { meconium }\end{array}$} & \multicolumn{2}{|c|}{$\begin{array}{l}\text { Moderate } \\
\text { meconium }\end{array}$} & \multicolumn{2}{|c|}{$\begin{array}{l}\text { Thin } \\
\text { meconium }\end{array}$} & \multicolumn{2}{|l|}{ Total } & \multicolumn{2}{|c|}{ Clear liquor } \\
\hline & $\mathbf{n}=\mathbf{3 3}$ & $\%$ & $n=43$ & $\%$ & $\mathrm{n}=42$ & $\%$ & $n=118$ & $\%$ & $\mathrm{n}=118$ & $\%$ \\
\hline $\begin{array}{l}\text { Oropharyngeal } \\
\text { suctioning }\end{array}$ & 13 & 39.39 & 28 & 65.11 & 36 & 85.71 & 77 & 65.24 & 104 & 88.13 \\
\hline $\begin{array}{l}\text { Endotracheal intubation } \\
\text { for suctioning followed } \\
\text { by extubation }\end{array}$ & 9 & 27.27 & 10 & 23.25 & 5 & 11.90 & 24 & 20.33 & 4 & 3.38 \\
\hline $\begin{array}{l}\text { Endotracheal intubation } \\
\text { and mechanical } \\
\text { ventilation }\end{array}$ & 10 & 30.30 & 5 & 11.62 & 1 & 2.38 & 16 & 13.55 & 10 & 8.47 \\
\hline $\begin{array}{l}\text { Endotracheal intubation } \\
\text { and mechanical } \\
\text { ventilation }\end{array}$ & 1 & 3.03 & 0 & 0 & 0 & 0 & 1 & 0.84 & 0 & 0 \\
\hline
\end{tabular}

The need for endotracheal intubation and mechanical ventilation did not show significant difference in the number of cases registered i.e. (13.55\%) in meconium stained liquor and (8.47\%) in clear liquor group (chi square $=1.385, \mathrm{p}>0.05)$. Number of cases noted in the thick, moderate and thin meconium were $30.30 \%$, $11.62 \%$, and $2.3 \%$ respectively. This shows significantly higher number in thick meconium stained group.

The need of endotracheal intubation and resuscitation showed no significant difference between meconium stained $(0.84 \%)$ and clear liquor $(0 \%)(p>0.05)$ (Table 4$)$. There is no significant difference in the number of cases requiring NICU admission in meconium stained liquor (14.4\%) and clear liquor (9.3\%) $(\mathrm{Z}=1.214, \mathrm{P}>0.05)$.
Table 5: Comparison of neonatal complications in meconium and clear liquor group.

\begin{tabular}{|lll|}
\hline $\begin{array}{l}\text { Neonatal } \\
\text { complications }\end{array}$ & $\begin{array}{l}\text { Meconium } \\
\text { stained liquor }\end{array}$ & $\begin{array}{l}\text { Clear liquor } \\
\text { group }\end{array}$ \\
\hline Severe birth asphyxia & 6 & 4 \\
\hline Pneumonia & 6 & 3 \\
\hline Septicaemia & 4 & 2 \\
\hline $\begin{array}{l}\text { Meconium aspiration } \\
\text { syndrome }\end{array}$ & 1 & 0 \\
\hline $\begin{array}{l}\text { Hypoxic ischemic } \\
\text { encephalopathy }\end{array}$ & 0 & 1 \\
\hline Fresh still birth & 1 & 0 \\
\hline Neonatal mortality & 1 & 1 \\
\hline
\end{tabular}


Neonatal complications observed in the meconium stained liquor and clear liquor groups registered, no significant difference between the two $(p<0.05)$ for different types of complications as listed in Table 5.

Maternal complications in meconium stained liquor and clear liquor showed significant difference only in the cases of post dated pregnancies and maternal infections $(p<0.10)$. In both the cases meconium stained liquor showed significantly higher number of cases compared to clear liquor (Table 6).

No significant difference was noted in the mean gestational age in meconium stained liquor and clear liquor $(p>0.05)$. Gestational age of the clear liquor group is more consistent than that of the meconium stained liquor (Table 7).
Table 6: Comparison of association of maternal complications in meconium and clear liquor group.

\begin{tabular}{|c|c|c|}
\hline Maternal complication & $\begin{array}{l}\text { Meconium } \\
\text { stained liquor }\end{array}$ & $\begin{array}{l}\text { Clear } \\
\text { liquor }\end{array}$ \\
\hline $\begin{array}{l}\text { Pregnancy induced } \\
\text { hypertension }\end{array}$ & 8 & 5 \\
\hline Pre-eclampsia & 4 & 4 \\
\hline Post dated pregnancy & 8 & 2 \\
\hline $\begin{array}{l}\text { Intrauterine growth } \\
\text { restriction }\end{array}$ & 4 & 2 \\
\hline Oligohydramnios & 2 & 2 \\
\hline Gestational diabetes mellitus & 4 & 3 \\
\hline Anaemia & 1 & 3 \\
\hline $\begin{array}{l}\text { Premature rupture of } \\
\text { membranes }\end{array}$ & 2 & 2 \\
\hline Maternal infections & 3 & 0 \\
\hline
\end{tabular}

Table 7: Distribution of cases by duration of pregnancy.

\begin{tabular}{|c|c|c|c|c|c|c|}
\hline Gestational age in weeks & Meconium & liquor & Clear 1 & & $\mathrm{t}$ & p value \\
\hline & $n=118$ & $\%$ & $\mathrm{n}=\mathbf{1 1 8}$ & $\%$ & \multirow{6}{*}{1.25} & \multirow{6}{*}{$>0.05$} \\
\hline $37-38.6$ & 60 & 50.84 & 69 & 58.47 & & \\
\hline $39-40.6$ & 54 & 45.76 & 47 & 39.83 & & \\
\hline$>40$ & 4 & 3.38 & 2 & 1.69 & & \\
\hline \multirow[t]{2}{*}{ Mean gestational age in wks \pm SD } & $38.33 \pm 1.22$ & & $38.66 \pm$ & & & \\
\hline & $3.18 \%$ & & $2.25 \%$ & & & \\
\hline
\end{tabular}

\section{DISCUSSION}

In this study the incidence of meconium stained liquor was $9.89 \%$. There was no statistical significance found in the distribution of incidence of various grades of meconium, which was comparable to studies conducted by Patil $\mathrm{K}$ et al $(8.30 \%)$ and Arulkumaran S et al (8.6\%), but lesser compared to David AN, Njokanmaof Iroha E $(20.40 \%){ }^{8-10}$ In the present study $44.06 \%$ of MSAF group had normal vaginal delivery as compared to $48.30 \%$ in clear liquor group. Instrumental delivery was $14.40 \%$ in MSAF group as compared to $20.33 \%$ in clear liquor group. Similarly, caesarean delivery was $41.52 \%$ among MSAF group compared to $31.35 \%$ in clear liquor group. Amongst the MSAF groups, thick meconium had the highest $(78.78 \%)$ incidence of caesarean deliveries. Findings of this study were comparable to the study done by Akhtar $\mathrm{N}$ et al who found $46.1 \%$ of MSAF group had normal vaginal delivery as compared to $76.3 \%$ in clear liquor group. ${ }^{11}$ Vacuum delivery was $11.8 \%$ in MSAF group as compared to $4.9 \%$ in clear liquor group. Similarly, caesarean delivery was $40.2 \%$ among MSAF group as compared to $18.8 \%$ in clear liquor group. In the study conducted by Mst.Hosna Ara Khatun et $\mathrm{al}^{12}$ caesarean deliveries were high $(75 \%)$ in meconium stained liquor and it was much higher with thick meconium $(75 \%)$ as compared to the other grades of meconium. Espinheira MC et al found, that of all babies born through MSAF and admitted to Neonatal Intensive Care Unit $62.5 \%$ were delivered by caesarean section. ${ }^{13}$

Foetal heart rate did not show any statistical significance between the number of cases in meconium stained and clear liquor group with respect to normal, suspicious and abnormal heart rate pattern in our study. $21.18 \%$ of MSAF and $19.49 \%$ of clear liquor group had foetal distress. Similarly, Esphinheira MC et al found $27 \%$ of meconium stained liquor cases had foetal distress. ${ }^{13}$

APGAR score at 1 minute was significantly lower in meconium stained liquor to that in clear liquor $(p<0.01)$. APGAR score is more consistent in clear liquor than the meconium stained liquor however Apgar score at $1 \mathrm{~min}$ is significantly lower in thick meconium stained liquor. APGAR score at 5minutes did not show any significant difference between meconium stained liquor and clear group ( $>0.05)$, but Apgar score at 5 minutes was significantly low in thick meconium stained liquor group. Mst. Khatun HA et al also found that APGAR scores at 1 minute and 5 minutes were low in meconium stained liquor cases $\left(6.8 \pm 1.2\right.$ and $8.3 \pm 1.1$ respectively). ${ }^{12}$ Akhtar $\mathrm{N}$ et al studied that mean Apgar score of meconium stained liquor was significantly lower both at 1 minute $(6.0 \pm 1.9)$ and at 5 minutes $(7.9 \pm 1.9)$ compared to clear liquor group $\left(7.6 \pm 1.4\right.$ at 1 minute, $8.7 \pm 1.3$ at 5 minute). ${ }^{11}$ The difference was found significant both at 1 minute 
$(\mathrm{p}<0.001)$ and at 5 minutes $(\mathrm{p}<0.005)$. Mean Apgar score at 1 minute was $5.2 \pm 2.3$ in thick MSAF babies and $6.6 \pm 1.4$ in thin MSAF born babies. These findings were statistically significant $(\mathrm{p}<0.001)$. At 5 min mean Apgar score was $7.2 \pm 2.3$ in thick MSAF babies and $8.5 \pm 1.3$ in thin MSAF babies. These findings were statistically highly significant $(p<0.002)$. These results indicate that degree of staining of liquor significantly affects the foetal outcome. Esphinheira $\mathrm{MC}$ et al found first minute APGAR score below 7 in $70.3 \%$ and fifth min APGAR score below 7 in $23.6 \%$ of babies born with meconium stained liquor. ${ }^{13}$

Immediate oropharyngeal suctioning was needed in $65.24 \%$ neonates in meconium stained group whereas $88.13 \%$ in clear liquor group which had a significant statistical difference (chi square $=4.0248, \mathrm{p}<0.05$ ). This observation may be because according to hospital practices every newborn undergoes oropharyngeal suctioning immediately after delivery. Endotracheal intubation for suctioning followed by extubation registered significantly higher number of cases $20.33 \%$ in meconium stained liquor compared to clear liquor group $(3.38 \%)$ (Chi square $=14.28, \mathrm{p}<0.001)$. The need of endotracheal intubation and mechanical ventilation did not show any significant difference in the number of cases registered $(13.55 \%)$ in meconium stained liquor and $(8.47 \%)$ in clear liquor group (chi square $=1.385$, $\mathrm{p}>0.05$ ). Number of cases noted in the thick, moderate and thin meconium is $30.30 \%, 11.62 \%$ and $2.3 \%$ respectively. This shows significantly higher number in thick meconium stained group. The need of endotracheal intubation and resuscitation showed no statistical difference between meconium stained $(0.84 \%)$ and clear liquor $(0 \%) \quad(\mathrm{p}>0.05)$. In the study conducted by Esphinheira MC et al it was noted that intubation for tracheal aspiration of meconium followed by immediate extubation was performed in 28 (38.9\%) newborns, while intubation followed by meconium ventilation support was done in $21(29.2 \%) .{ }^{13}$ Whereas in, Khatun HA et al study requirement of oropharyngeal suction was more $(69.6 \%)$ in cases $(\mathrm{p}<0.001)$ as compared to controls and intubations needed only in meconium stained cases $(5 \%){ }^{12}$ Studies suggest that intrapartum suctioning may be effective for decreasing the risk of aspiration syndrome but evidence from large trial did not show such an effect. ${ }^{14-17}$ If the infant is vigorous endotracheal suction is not recommended because it may cause harm and does not improve neonatal outcome. ${ }^{18}$

More than 3 days of overall stay in hospital was needed in $46.61 \%$ of meconium stained liquor cases compared to $31.35 \%$ in clear liquor group. More than 10 days of overall stay in hospital was needed in $11.01 \%$ of meconium stained liquor cases compared to $8.47 \%$ of clear liquor group. Whereas neonatal intensive care was needed in $14.4 \%$ newborns born through meconium stained liquor than $9.3 \%$ of newborns born in the clear liquor group which was not statistically significant $(\mathrm{z}=1.214, \mathrm{p}>0.005)$.
Khatun HA et al showed that admission in neonatal ward was more $(22.5 \%)$ in cases $(\mathrm{p}<0.05)$ as compared to control. ${ }^{12}$ Akhtar $\mathrm{N}$ et al studied that amongst the babies born with MSAF $18.8 \%$ and babies born with clear liquor only $8.8 \%$ were admitted to neonatal intensive care unit. ${ }^{11}$ Neonatal intensive care unit stay was prolonged with presence of thick meconium.

According to our study neonatal complications observed in meconium stained liquor and clear liquor group registered no statistical significance between the two ( $p>0.05$ ) for different types of complications; such as severe birth asphyxia (5.08\% vs. $3.38 \%)$, pneumonia $(5.08 \%$ vs $2.54 \%)$, septicaemia $(3.38 \%$ vs $1.69 \%)$, meconium aspiration syndrome $(0.84 \%$ vs $0 \%)$, hypoxic ischemic encephalopathy ( $0 \%$ vs $0.84 \%)$, fresh still birth $(0.84 \%$ vs. $0 \%)$ respectively. Only one fresh still birth occurred in meconium stained liquor group, which was a referral from a peripheral hospital for obstructed labour with thick meconium. Neonatal mortality observed in the meconium stained liquor and clear liquor group showed no significant difference between the two $(p>0.05)$. According to the study by Velaphi $\mathrm{S}$ et aland Wiswell $\mathrm{TE}^{20}$, even with modern neonatal intensive care, mortality from meconium aspiration syndrome remains high, in the range of $3-5 \% .^{19,20}$

Khatun HA et al study, birth asphyxia was more (20\%) in cases $(p<0.05)$ than in controls $(6.3 \%) .{ }^{12}$ Requirement of oropharyngeal suction was also more $(69.6 \%)$ in cases $(\mathrm{p}<0.001)$. Intubations were needed only in $5 \%$ cases. Meconium aspiration syndrome and convulsions developed only in meconium stained liquor cases which were $25 \%$ and $3.8 \%$ respectively. Admission to neonatal ward was more $(22.5 \%)$ in cases $(\mathrm{p}<0.05 \%)$. Neonatal mortality was also high in cases than controls but it was not statistically significant $(\mathrm{p}<0.05)$ and there was no still birth. In study by Espinheira MC et al morbidity was not statistically significant and hypoxia (58.3\% of cases) was the most frequent complication, followed by the need for ventilator support $(43.1 \%$ of newborns), metabolic acidosis in $30.6 \%$, pulmonary hypertension in $11.1 \%$ and hypoxic-ischemic encephalopathy in $29.2 \%$ of cases. Mortality rate observed was $2.8 \%{ }^{13}$ Study done by Akhtar $\mathrm{N}$ et al found that majority of those who were admitted to SCBU, $6.9 \%$ were diagnosed having moderate birth asphyxia (on the basis of Apgar score at 1 minute) and this was only $1.9 \%$ among clear liquor born babies. ${ }^{11}$ Similarly, $2.9 \%$ of admitted babies were diagnosed as severe birth asphyxia as compared to $0.9 \%$ babies with clear liquor. $1.9 \%$ babies with MSAF were diagnosed with meconium aspiration syndrome. In this study one baby in clear liquor group was still born, in MSAF group no baby was still born but two babies with thick meconium had neonatal deaths (1.9\%).

In our study impact of maternal complications on meconium stained liquor and clear liquor showed significant difference only in the cases of post dated pregnancies $(6.77 \%$ vs. $1.69 \%)$ and maternal infections 
$(2.54 \%$ vs. $0 \%)(\mathrm{p}<0.10)$. In Khatun HA study $13.8 \%$ had pregnancy induced hypertension compared to $3.8 \%$ in controls $(\mathrm{p}<0.05) .{ }^{12}$ Preeclampsia was present in $10 \%$ of meconium stained liquor as compared to $1.1 \%$ in clear liquor $(\mathrm{p}<0.05)$.

In the study by Espinheira MC et al found pregnancy related complications in meconium stained liquor was $22.2 \%$ in post dated pregnancies whereas pregnancy induced hypertension was observed in $2.8 \%$, oligohydramnios in $1.4 \%$ and intrauterine growth restriction in $1.4 \%$ of cases. ${ }^{13}$

In this study mean birth weight of babies in meconium stained liquor $(2.97 \pm 0.48 \mathrm{~kg})$ is significantly higher than that in clear liquor $(2.83 \pm 0.56 \mathrm{~kg})(\mathrm{p}<0.05)$. Birth weight is more consistent in meconium stained liquor compared to that in clear liquor group. Similar results were observed in Khatun HA study. ${ }^{12}$ Mean birth weight was $2.9 \pm 0.4 \mathrm{~kg}$ in cases compared to controls $(2.8 \pm 0.4 \mathrm{~kg})$ ( $\mathrm{p}<0.01)$. Espinheira $\mathrm{MC}$ et al had noted a mean birth weight of $3295 \pm 491$ grams in meconium stained liquor. ${ }^{13}$ But Neke Akhtar et al ${ }^{11}$ found that low birth weight $(<2.5$ $\mathrm{kg}$ ) was more common $23(22.5 \%)$ in MSAF group compared to $12(11.3 \%)$ in clear liquor group.

After analysis of mean gestational age; no significant difference can be noted in the meconium stained (38.33 $\pm 1.22)$ and clear liquor group $(38.66 \pm 0.87)(\mathrm{p}>0.05)$. Conversely in other studies like Khatun HA study the mean gestational age of meconium stained liquor $(39.3 \pm 1.5 \%)$ is significantly higher than that of clear liquor $(38.5 \% \pm 1.3 \%){ }^{12}$ Akhtar $\mathrm{N}$ et al has found that majority of the mothers with MSAF were within 3738weeks. ${ }^{11}$ The gestational age of the mother with MSAF group was $38.9 \% \pm 1.8 \%$ weeks and that of clear liquor group was $38.5 \pm 1.3 \%$ weeks. Espinheira MC et al noted that mean gestational age of cases of meconium stained liquor was $39.5 \pm 1.63$ ) weeks, of which $70.8 \%$ were term and $22.2 \%$ were post term cases. ${ }^{13}$

\section{CONCLUSION}

Meconium staining is a commonly observed phenomenon. Thick meconium stained liquor during labour is associated with increased incidence of perinatal morbidity. Hence labour complicated with thick meconium stained liquor should ideally be categorised in to high risk obstetrics and managed in tertiary care with consultant obstetrician, consultant neonatologist and Neonatal Intensive Care Unit in order to improve the perinatal outcome.

All patients with meconium stained liquor should ideally be managed in labour with continuous foetal heart rate monitoring. Mode of delivery should be decided according to modified Bishops score and degree of foetal distress. Meconium stained liquor does not have any impact on increase in overall caesarean rate.
Funding: No funding sources

Conflict of interest: None declared

Ethical approval: The study was approved by the Institutional Ethics Committee at Lourdes hospital, Cochin, Kerala

\section{REFERENCES}

1. Berkus MD, Langer 0, Samuelloff A, Xenakis EM, Field NT, Ridgeway LE. Meconium stained amniotic fluid: increased risk for adverse outcome. Obstet Gynecol. 1994;84:115-20

2. Nathan L, Leveno KJ, Camody TJ 3'd, Kelly MA Sherman ML. Meconium: a1990s perspective on an old obstetric hazard. Obstet Gynecol. 1994;83:32932.

3. Low JA, Pancham SR, Worthington, Bolton RW: The incidence of fetal asphyxia in 600 high risk monitored pregnancies. Am J Obstet Gynecol. 1975;121:456-9.

4. Meis PJ, Hall M, Marshall JR, Hobel CG. Meconium passage; a new classification for risk assessment during labour. Am J Obstet Gynecol. 1978;131:50913.

5. Fujikura T, Klionsky B. The significance of meconium staining. Am J Obstet Gynecol. 1975;121:45-50.

6. Miller FC. Meconium staining of the amniotic fluid. Clinics Obstet Gynecol. 1979;6:359-65.

7. D.C. Dutta Text book of obstetrics 6th edition, Calcutta, New central book agency;2004:610.

8. Patil Kamal P, Swamy MK, Samatha K. A one year cross sectional study of management practices of meconium stained amniotic fluid and perinatal outcome, J Obstet Gynecol. 2006; 56(2):128-30.

9. Arulkumaran S, Yeoh SC, Gibb DM, Ingemarsson I, Ratnam SS. Obstetric outcome of meconium stained liquor in labour. Singapore Med J. 1985 Dec;26(7):523-6.

10. David AN, Njokanma OF, Iroha E. Incidence of and factors associated with meconium staining of the amniotic fluid in a Nigerian University Teaching Hospital. J Obstet Gynaecol. 2006 Jan 1;26(6):51820.

11. Akhtar N, Fazilatunnesa, Yasmeen S. Mode of delivery and fetal outcome in meconium stained amniotic fluid (MSAF), Dhaka Medical College Hospital, Dhaka, Bangladesh;2006.

12. Khatun MH, Arzu J, Haque E, Kamal MA, Al Mamun MA, Khan MF, Hoque MM. Fetal outcome in deliveries with meconium stained liquor. Bangladesh J Child Health. 2009;33(2):41-5.

13. Espinheira MC, Grilo M, Rocha G, Guedes B, Guimarães H. Meconium aspiration syndrome: the experience of a tertiary center. Rev Port Pneumol. 2011;17(2):71-6.

14. Carson BS, Losey RW, Bowes WA Jr, Simmons MA. Combined obstetric and paediatric approach to prevent meconium aspiration syndrome. Am J Obstet Gynecol. 1976;126:712-5. 
15. Falciglia HS, Henderschott C, Potter P, Helmchen R. Does Delee. Suction at the perineum prevent meconium aspiration syndrome? Am J Obstet Gynecol. 1992;167:1243-9.

16. Wiswell TE, Gannon CM, Jacob J, Goldsmith L, Szyld E, Weiss K, Delivery room management of the apparently vigorous meconium-stained neonate: results of the multicentre, international collaborative trial. Pediatrics. 2000;105:1-7.

17. Vain NE, Szyld EG, Prudent LM, Wiswell TE, Aguilar AM, Vivas NI. Oropharyngeal and nasopharyngeal suctioning of meconium-stained neonates before delivery of their shoulders: multicentre randomised controlled trial. Lancet. 2004;364:597-602.

18. Harris AP, Sendak MJ, Donham RT. Changes in arterial oxygen saturation immediately after birth in the human neonate. J Pediatr. 1986;109:117-9.
19. Velaphi S, Vidyasagar D. Intrapartum and postdelivery management of infants born to mothers with meconium-stained amniotic fluid: evidencebased recommendations. Clin Perinatal. Mar 2006;33(1):29-42.

20. Wiswell TE. Advances in the treatment of the meconium aspiration syndrome. Acta Paediatr Suppl. 2001;90(436):28-30.

Cite this article as: Patil AN, Inamdar MM,

Senapati JB. Study of perinatal outcome of labour complicated with meconium stained liquor. Int $\mathbf{J}$ Reprod Contracept Obstet Gynecol 2018;7:3582-9. 